\title{
Adopting Technology: Using Student Qualitative Data and Gartner's Hype Cycle
}

\author{
Trent Grundmeyer \\ Correspondence: Trent Grundmeyer, School of Education, Drake University, Des Moines, IA, USA
}

Received: September 29, 2013 Accepted: October 17, 2013 Online Published: November 12, 2013

doi:10.11114/jets.v2i1.228

URL: http://dx.doi.org/10.11114/jets.v2i1.228

\begin{abstract}
Technology is changing education. School leaders are charged with purchasing and leveraging technology to maximize an ever-changing landscape of teaching and learning. They have many factors to consider as they make decisions about what specific technologies to purchase for their schools. Gartner's Hype Cycle is an annually published report that can help school leaders anticipate and plan for trends in education. A recent qualitative study analyzed data from fifteen participants in two different countries and five different high schools regarding their one-to-one (1:1) laptop experiences. The study used a phenomenological strategy to explain first-year college students' perceptions of the effects of a 1:1 laptop experience on their readiness for college and the uses of technology for instructional purposes by high school teachers and college professors. Implications from the study for school leaders call for technology initiatives to be thoughtfully planned and sustainable. Preparation for implementation should include infrastructure planning, clear and measureable goals for the initiative that are effectively communicated to the stakeholders involved in the initiative, and effective training for teachers prior to and during the technology initiative. The results of the 1:1 qualitative study used in conjunction with Gartner's Hype Cycle provide critical information for school leaders to consider when determining the selection and timing of technology initiatives and planning for implementation.
\end{abstract}

Keywords: technology, technology adoption, school reform, technology integration, 1:1 laptop initiative

\section{Introduction}

Schools today are given the task of not only educating students with the three Rs of Reading, wRiting, and aRithmetic but also are expected to help students develop strong backgrounds in science, technology, global studies, and a diversity of so-called 21st century skills such as critical thinking, collaboration, agility, initiative, oral and written communication skills, ability to analyze information, and imagination (Wagner, 2008). Attention has turned to the use of technology to help achieve these goals in many school districts. Despite current budget challenges, 65 percent of school districts in the United States plan to increase technology investments in the classroom over the next two years (CDW Government, 2012). It is imperative that school leaders are able to navigate technology decisions to capitalize on taxpayer dollars that fund public schools to provide the best technology for their students and staff. One recent study provided insight to school leaders about technology adoption. Coupled with Gartner's Hype Cycle, school leaders have the data and awareness to make sound technology adoption decisions for their schools.

\subsection{Purpose of the Study}

The purpose of a recent qualitative study was to obtain feedback from students about how their high school 1:1 laptop initiative prepared them for college. Specifically, the study examined the perceptions of first-year college students who had experienced 1:1 laptop initiatives for a minimum of two years in high school. The second purpose for the study was to uncover student perceptions about their high school teachers' use of technology for instructional purposes. Two research questions guided this study:

1) What are first-year college students' perceptions of the relationship between their high school 1:1 laptop experiences and their readiness for college?

2) What are first-year college students' perceptions of the uses of technology for instructional purposes by high school teachers? 


\subsection{The Evolution in Technology in Public K-12 Schools}

Since the late 1970s, there has been a rapid growth in the use of computers throughout PreK-12 education (Hermes, 2009). When computers were first introduced into schools, they were used largely for secretarial tasks and administrative purposes (Schifter, 2008). During this time, computers increased administrative efficiency in many areas including processing and printing student schedules, monitoring library usage, storing student and faculty records, taking inventory, and doing accounting tasks. Schools were able to produce and maintain financial accounts and student reports. Computers helped improve organizational accuracy and efficiency. Computers were used to calculate student grades, which saved teachers time and energy compared to previous methods of scoring and grading. In addition, teachers could create and store individualized student records with details about students' needs, academic progress, and social development.

In the 1980s, educators began using computers for instructional purposes, including preparing lesson plans, work sheets, tests, and reports. Thus, computers enhanced teachers' productivity, accuracy, and ability to analyze data in order to improve teaching and learning in the classroom (Murdock, 2004).

In time, educators expanded their use of computers and are now utilizing them for a variety of purposes. Many educators utilize computers on a daily basis to blog, engage in online learning networks, Skype with other classes, use online textbooks, and utilize Web 2.0 tools. The use of computers in education has dramatically increased and is only limited by time for training and hardware that varies among schools.

Research and survey data indicates that computer usage in PK-16 schools has grown significantly. The percentage of American schools with at least one computer rose from 18\% in 1981 to 95\% in 1987 (Hermes, 2009). In 1983, $40 \%$ of elementary schools and $75 \%$ of secondary schools used computers for instruction (Murdock, 2004). By 1985, one million schools had computers (Murdock, 2004). In 1995, there were 5.8 million computers in U.S. schools (Schifter, 2008). In 2003, all (100\%) of American schools had access to the Internet (Schifter, 2008). Today, almost every teacher in the nation has a computer in his or her classroom (Hermes, 2009). Curriculum content ensures students have computer experience in many subjects and in many formats, ranging from games that teach multiplication tables to Internet-based research projects (Murdock, 2004).

\subsection{Benefits of Computer Use in Education}

Educators are continuously searching for ways to increase high school graduates' college readiness. Increasing attention is being given to 1:1 computer initiatives as a vehicle for improving college readiness and improving teaching and learning. Recognizing that we now live in a digital rather than analog world, many schools are implementing 1:1 computing initiatives to help accomplish these academic goals and many others are considering making the transition (McLeod \& Sauers, 2010). Schools use a variety of tools, particularly effective instruction and technology, to engage students and increase student achievement (Schifter, 2008).

Today's school-aged children have grown up with technology. Students today expect to have technology available. On average, 13- to 18-year-olds spend more than six hours per day using digital media (Metiri Group, 2006). However, schools typically have not capitalized on the tools and technologies that often engage students. Further, although outside of school students instant message, download and listen to music, compose and send emails, watch television, exchange text messages and digital images via cell phone, browse the web, and play interactive games, such facility with technology should not be mistaken for expertise or literacy with technology (Metiri Group, 2006). Most students are in direct need of conventions that will enable them to use technologies to prepare them for college and work (Metiri Group, 2006). In other words, most students need access to and skill in using technologies to develop and utilize 21 st century skills such as critical thinking, creativity, social adeptness, and complex communication skills as well as proficiency in the areas of finances, technology, health, civics, and employability skills.

Results of various research studies and surveys indicate that teachers tend to understand that technology engages students and can improve learning. For example, in a landmark study of 40,000 teachers conducted by Scholastic, Inc. and the Bill and Melinda Gates Foundation (Primary Sources, 2010), participants were asked two questions that are of importance to the present study. First, when asked what engages students in learning, 57\% agreed strongly and 38\% agreed somewhat that digital resource such as classroom technology, and web-based programs engage their students in learning. In comparison, only $6 \%$ of participants agreed strongly and $40 \%$ agreed somewhat those traditional textbooks engage their students in learning.

Responses to a second question indicated that $44 \%$ of participants agreed strongly and $49 \%$ agreed somewhat those digital resources such as classroom technology and web-based programs help their students' academic achievement. In contrast, $12 \%$ of participants agreed strongly and 57\% agreed somewhat that traditional textbooks help their students' academic achievement. 


\subsection{Challenges for Computer Use in Education}

Despite the advances of computer use in schools and support from educators, challenges persist. Money is a particularly important issue. Administrators identify limited state funding as an ongoing barrier to offering more online courses (Project Tomorrow, 2011). Administrators acknowledge that, with recent budget constraints, paying teachers to create online courses has been put on the back burner despite the possible benefits. Another barrier to improved technology use in education is the demands of teacher training. In a recent survey of students, faculty, and information technology staff, $16 \%$ of information technology professionals reported teachers' lack of training as the "biggest challenge of classroom technology" (CDW, 2011).

Shifter (2008) identified several additional challenges. A primary issue is accessibility. Although access to computers has risen sharply, the amount of time that most students spend on computers at school has not significantly changed and their primary access to computers still is in computer labs or libraries (Schifter, 2008). Utilizing a computer is still an episodic event for most students rather than a routine part of the school experience. This is true in 1:1 schools as well as schools who host traditional computer labs. Second, there are inequities across schools. Up-to-date computers are more likely to be found in affluent, suburban schools while less affluent inner city or rural schools usually have older models, despite the fact that the No Child Left Behind Act of 2001 requires all students to be computer literate by the eighth grade (Schifter, 2008). Third, teachers do not have routine time to identify ever-changing digital resources so they often resort to utilizing the same resources that they have used for years. Finally, because computer technology is an ever-advancing industry, it has been difficult for schools to keep up with technology advancements (Schifter, 2008). Each time computing power or technology increases, public schools, given their limited capacity and budgets, are left with outdated computer models and software (Schifter, 2008).

\subsection{Understanding Gartner's Hype Cycle}

Gartner, Inc. is an information technology and advisory firm located in Stamford, CT that was founded in 1979. The company employs 5,700 associates which includes 1,435 research analysts and consultants. Gartner, Inc. has clients in 85 countries around in a broad variety of enterprises. The mission of the organization is to provide technology related insight, targeting chief information officers and technology leaders around the world. Gartner traditionally uses hype cycles and Magic Quadrants for visualization of its market analysis results.

Gartner's Hype Cycle is a graphic representation of the maturity, adoption, and social applications of specific technology (Gartner, 2013). According to Gartner, hype cycles aim to separate the hype from the reality and enable organizations to decide whether a particular technology is ready for adoption. The cycle can offer potential benefits to teaching and learning and can provide school leaders with a snapshot of what innovations are on the horizon.

The Hype Cycle is updated annually to track technologies along this cycle and provide guidance on when and where organizations should adopt them for maximum impact and value. Gartner's 2013 Hype Cycle lists over 2000 technologies, grouped into 102 distinct areas. Gartner has used the Hype Cycle tool since 1995 to highlight the common pattern of over enthusiasm, disillusionment, and eventual realism that accompanies each new technology and innovation (Fenn \& Raskino, 2013).

The Hype Cycle is set up in a predictable shape that defines the mainstream adoption pattern of technologies. Figure 1 is a theoretical Hype Cycle model that illustrates how the adoption of an innovation typically occurs.

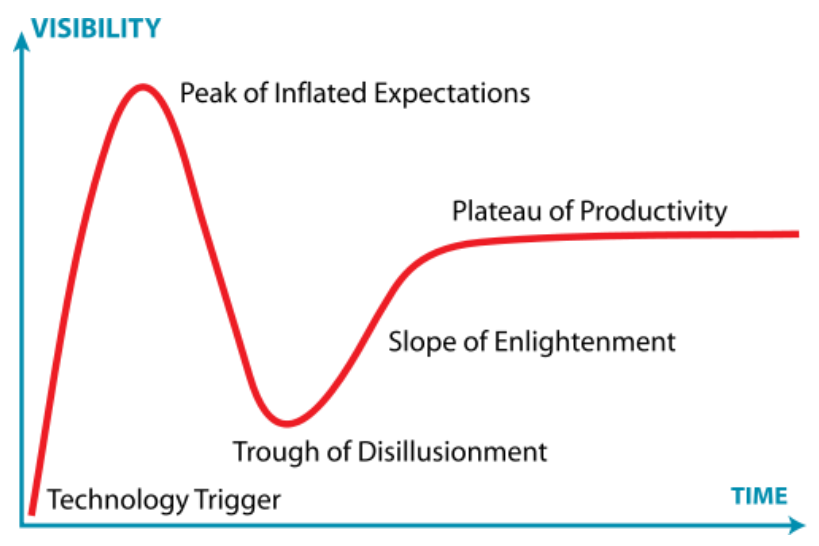

Figure 1. Gartner's Hype Cycle

Description: A graphic generalization of the influences of visibility and time onthe mainstream adoption pattern of technologies. 
A technology trigger often sparks the interest of people. This is often done through marketing and advertising of a new product. Because of the high expectations, people or organizations often have a "peak of inflated expectations" for a short period followed by a short period of disappointment known as the "trough of disillusionment." The next stages in the cycle occur because of product upgrades and/or changes to marketing, as well as realignment of consumer expectations. During a "slope of enlightenment," people and organizations start to understand and become aware of how the innovation may benefit them. Second and third generation products normally appear during this state of adoption. In the "plateau of productivity" mainstream adoption of the innovation begins to take off.

If an innovation has just started and is on the rise, it may be useful to learn about or get a head-start piloting in the education setting. However, this may be a high risk for school leaders and ill advised until the innovation is more widely tested in an education setting. Innovations at the peak or sliding into the trough of disillusionment tend to be well known and have serious potential. Those innovations found climbing the slope of enlightenment and entering the plateau of productivity are considered by Garner as mature and stable for education mainstream adoption. These would be considered good investments for school leaders.

1.6 Gartner's Hype Cycle, 2013

The 2013 Hype Cycle, Figure 2, provides calculated insight on potential innovations for education leaders in the future (Gartner, 2013). The 2013 Hype Cycle contains technologies applicable to education at the following stages:

Technologieson the rise-Mashware, Quantum Computing, Education Tablet, Campus App Store, Student Retention CRM, Citizen Developers

At the peak- Adaptive e-textbooks, Big Data, Gamification, MOOC, Social Software Standards, Adaptive Learning

Sliding into the trough-Digital Preservation of Research Data, BYOD Strategy, Mobile-Learning Low-Range Handsets, Open-Source Financials, Web-Based Office Productivity Suites, Social Learning Platform for Education, Mobile-Learning Smartphones, E-Textbooks, Cloud Email for Staff and Faculty, Virtual Environments/Worlds

Climbing the Slope-Mass Notification Services, Hosted Virtual Desktops, Open-Source Learning Repositories, IT Infrastructure Utility, Intellectual Property Rights and Royalties Management Software, Unified Communications and Collaboration, Tablets, Game Consoles as Media Hubs

Entering the plateau-E-Book Readers, Self-Publishing, Mashups

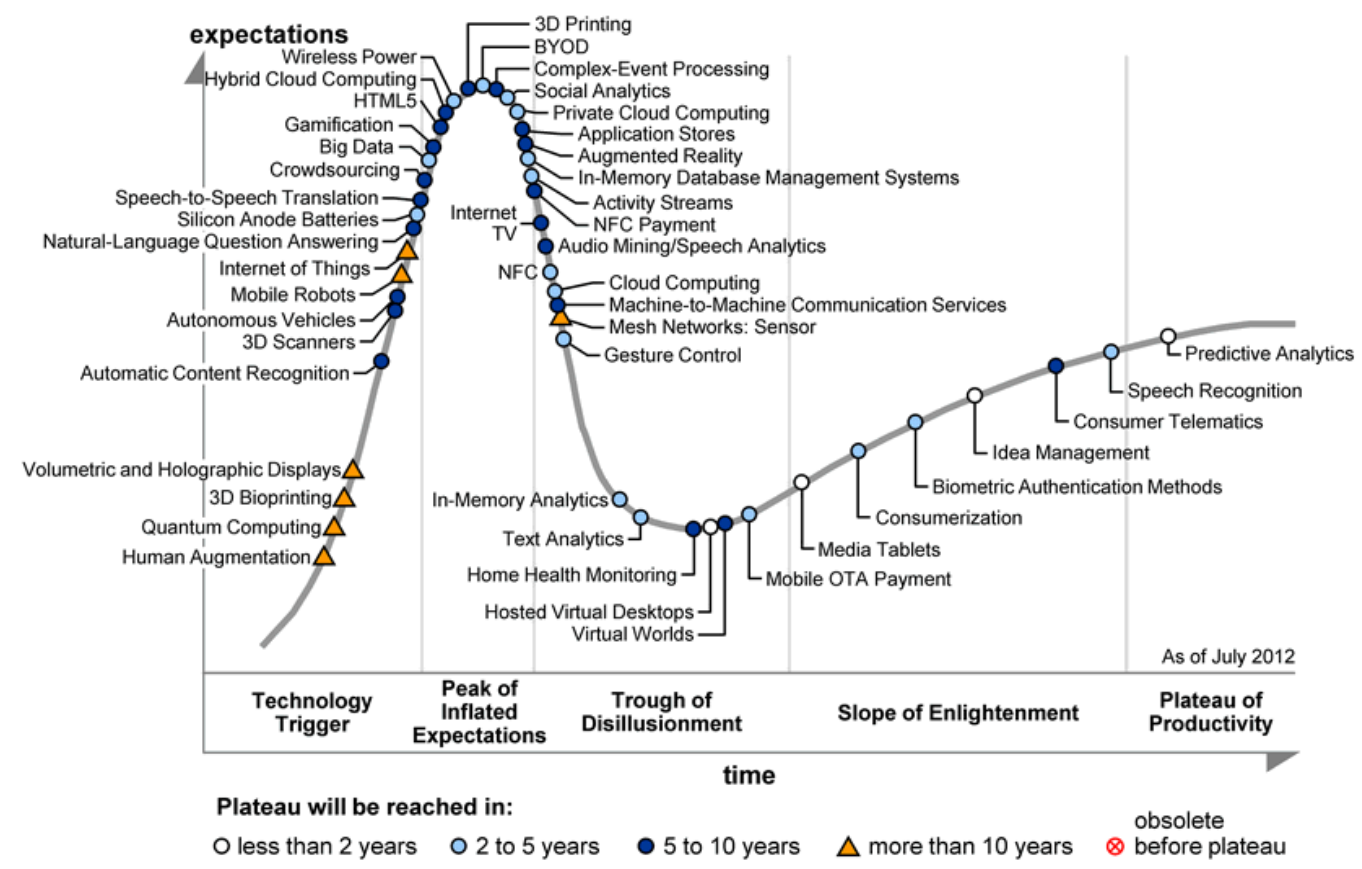

Figure 2. Gartner's Hype Cycle, 2013

Description: Gartner's Hype Cycle for 2013, which places technologies on an adoption cycle based on their maturity, adoption, and future direction. 


\subsection{Reviewing Gartner's Hype Cycle for Education, 2009}

Past Hype Cycles from Gartner reveal the accuracy of the model. In 2009, innovations such as cloud emailing and podcasting learning content were all ready for mainstream adoption (Gartner, 2009). Four years later it is understood that these innovations have been adopted in most schools and are widely used by educators. Other innovations on the 2009 Hype Cycle were further away from widespread adoption but were noted in the "trough of disillusionment." These potential innovations included e-learning repositories, virtual worlds, lecture capture and retrieval tools, and e-textbooks. In comparing some of these technologies that were originally further away from mainstream adoption one can see the advancement of certain technologies in education. E-textbooks and virtual worlds remain in the trough of disillusionment while E-learning repositories and lecture capture and retrieval tools are climbing the slope of enlightenment on the most recent hype cycle reports.

Given the prior accuracies, Gartner's current Hype Cycle can offer key insightson when school leaders should consider technology adoption and how new innovations may change their learning enviornments. Understanding the path of the Hype Cycle can also be useful in navigating through phases of implementation to put adopted technologies into a phase of productivity as quickly as possible.

\section{Methods}

The qualitative research methods used for the 1:1 laptop experiences study included purposive sampling, open-ended interviewing, and systematic and concurrent data collection and data analysis procedures. Specifically, the grounded theory or constant comparative method (Glaser \& Strauss, 1967) was used to analyze the data and discover the meaning of college freshmen's 1:1 laptop experiences. A review board approved the purpose and procedures for the study.

\subsection{Participants}

First-year college students who had a minimum of two years experience with a 1:1 laptop initiative in high school and who had completed a minimum of one semester of college acted as participants in this study since they would be "knowledgeable informants" (Lincoln \& Guba, 1985, p. 234). Because the goal of the study was to uncover student perceptions of a 1:1 initiative during their first-year of college, it was important that participants had completed at least one semester of college. The experiences that participants had during this first semester of college gave them a basis from which to compare their college readiness to other first-year college students who were not exposed to a 1:1 laptop initiative in high school.

Solicitation for participants in the study was outlined in a call to school principals in 36 high schools across the United States. These principals were asked to provide the names and contact information of potential participants who met the criteria for the study. Once names and contact information was gathered, the researcher contacted each first-year college student to ensure they met the criteria to serve as a participant in the study. Upon consent, interviews were set up with each participant.

\subsection{Interviews}

A total of fifteen participants were interviewed by phone for this qualitative study. Interviews used semi-structured approach to provide a framework for the interview but also allow the researcher to ask other questions that bolstered the depth, clarification, and understanding of the participants' responses. Interviews ranged from forty minutes to ninety-eight minutes in length. Participant demographics included twelve participants from the Midwest, two from the east coast, and one residing in Thailand.

Each interview was recorded and transcribed for accuracy and detail. The researcher also took field notes during the interview. Topics addressed in the field notes included particular events that participants recalled, the researcher's speculations about emerging themes, points of clarification, and any connections that the researcher detected between or among participants' perceptions (Bogdan \& Biklin, 1982).

\subsection{Data Analysis}

Analysis occurred in three phases. First, interview transcripts were reviewed several times, searching for "recurring regularities" (Merriam, 1998, p. 180). The researcher highlighted quotes and phrases from the interviews that were significant to the study. Using the constant comparative method (Glaser \& Strauss, 1967), the researchers went back and forth among transcripts until categories emerged that were consistent, yet distinct (Marshall \& Rossman, 1989). The researcher named these categories, coded the transcripts, and placed sections in labeled folders representing each categories (Bogdan \& Biklin, 1982; Merriam, 1998). Second, the researcher brought together the coded interviews and field notes and looked for relationships within and across the data 
sources. As tentative categories emerged, the researcher tested them against the data (Merriam, 1998). Finally, the researcher integrated and refined the categories until themes solidified (Strauss \& Corbin, 1998).

\section{Discussion}

Thelaptop experiences of students in the 1:1 study yielded valuable informationfor school leaders for succesful technology adoption. This data, in conjunction with knowledge about Gartner's Hype Cycle, provide a powerful platform for school leaders to make technology adoption and planning decisions for their school districts.

In the 1:1 study, the implementation dip was a period of time in which new technology was not fully or effectively utilized in this study. Students reported that these implementation dips were noticeable and detrimental to their academic success at times, and often persisted throughout a semester or even an entire year.

Three major themes resulted from the insight of student particiants in the 1:1 study. These themes suggested distinct issues to be addressed in the planning phase of adopting new technologies in order to mitigate a period of disppointement or frustration after adoption.

\subsection{Infrastructure Planning for Technology}

Since most schools put newly leased or purchased laptops on a three to four year rotation, ongoing service and upkeep for the laptops is important. Many students in the study reported frustration about the condition of their laptops. Participant 13 reported frustration with their laptop when repairs were needed:

Many students were frustrated with repairs during the third year with the laptops. It sucked when a computer was slow and they couldn't be fixed or repaired. Tech staff often seemed to be more concerned with new features than repairing old machines for students.

Participant 10 further highlighted frustrations the upkeep of the laptops, saying, "Financing seems to be a huge issue for schools so that they are able to have up-to-date technology. The school has low bandwidth, thus slow Internet access speed, which inhibits students from using the technology."

Multiple participants commented about negative experiences with damaged or broken laptops. Whether it is a laptop computer or another technology resource supported by the school district, the condition of the device must be functional for students and staff to fully leverage its benefits. Most of the experiences that students shared happened when the computer was three or four years old.

Although students and parents often are responsible for laptop damage, such damage is inevitable. In general, participants reported that keeping their laptop in good working condition was very important. When their laptop was not working, it seemed to have a significant impact on the students' academic work. In planning for technology adoption, school leaders must consider the cost of on-going and inevitable repairs to keep the technology fully functional.

\subsection{Technology Initiative Goals and Evaluation}

Participants were asked if they knew how the 1:1 laptop programs that they experienced in high school were evaluated for effectiveness. The responses to this question were less confident and more diverse than those given regarding why their high school adopted a 1:1 initiative. For instance, Participant 12 elaborated on his thoughts about how he believed a 1:1 program was evaluated by saying:

Our school has always had good standardized testing scores. I think the evaluation of the initiative in the first two years was a drop in our standardized testing. The first-year we had it (laptop initiative) especially was just trial and error and trying to get things right. The head of academics, or whatever she is, came into classrooms, and I think a lot of time she would try to find out how effectively the computers were being used. I mean I think they were still determining the way to kind of evaluate us I guess.

Participant 4 simply said, "I'm not sure if we had an official evaluation, but in my opinion it is really effective." Participant 10 directly stated they had no idea how the project was evaluated. Participant 14 didn't know either, "I can't say that I know. I really don't know how they would gauge whether it's worth it or not. I think it was personally, but there was no way to tell if we were performing better or not because of the computers."

Student participants in this study concluded that the goals and desired outcomes of the 1:1 initiative were not clear to students or staff. Unclear or poorly-communicated goals and evaluation measures of the 1:1 initiatives that the students experienced were possible reasons for the noticeable implementation dips and disillusionment.

Prior to adopting a technology initiative, school leaders should solicit input from stakeholder groups about the desired goals and measureable outcomes they hope to gain from investing in technology. The adoption should be deliberate and followed by measurable outcomes that can provide a value analysis on the investment for all 
involved in the purchasing decisions. School leaders who are aware of the Hype Cycle would be able to anticipate the trajectory of the technology adoption and as a result, have time to establish desired outcomes for the new technology initiative. Goals and outcomes of a technology initiative should also be communicated to students and parents so that they understand why the district made the investment and what they hope to gain from the technology investment.

\subsection{Staff Training}

Participant 13 said, "I feel if a school is going to have a 1:1 initiative they should know how to use them. If the teachers don't know how to use them it is a real issue." The data from participants made it clear that there had been insufficient training for staff related to the laptop initiative and consequently the new device wasted valuable classroom instructional time and was often a distraction for both students and teachers.

Since many of the participants experienced the initial rollout of laptop computers in their high schools, they were able to compare the first year of implementation with later years. For instance, Participant 14 said, "It seemed like it took a semester to get over the distraction of the laptop and have teachers fully use it in different and better ways. It seems like the program was getting better and better over time." Similarly, Participant 7 stated, "The teachers didn't seem to be as effective using the laptops the first year. Once schools learn how to use the laptops effectively the laptop is a very good tool." Students reported that both students and teachers seemed to have real challenges to address once the laptops were first rolled out. Participant 12 noted:

I think some of the disadvantages were just because of the first-years of using the laptop. I think we did a lot of things using trial and error. I think some of the courses were a little bit harder to integrate the computers into, so I feel like some of the courses were a little astray sometimes. Besides that there were little, if any, disadvantages to having the laptop in high school.

Participant 10 agreed:

A lot of people thought it (laptops) just for games and iChat, and it was a little bit of a distraction. It took us like a semester to kind of get over that stage of thinking that it was just a toy. I know my senior year people were a lot more mature about it and we started using them (laptops) a lot more for different and better ways. I think even from the teacher's perspective my teachers didn't really know how to use them at first to make it help us learn better.

Participant 13 concurred, stating:

Well, I think that basically the first-year we started using laptops, we were all just getting the hang of it, getting the hang of that computers and stuff, so I feel like we used it for a lot more presentations and we kind of ease into it. So, it seemed to take awhile before we started to use the computer for other things like PowerPoint and other things like that.

Technology can become a distraction to the educational environment if not used as an effective learning tool and the insufficient training for staff in the 1:1 study did result in student distractions. Minimizing the distractions from new technology adoption requires that teachers have the skills and training to fully leverage the new technology for instructional purposes. A number of respondents noted that sometimes having a laptop while in high school distracted them personally or other peers. Examples included students working on personal projects during class time, social networking during classes, playing games during school, and looking up inappropriate pictures or content during school. The case is clear that students acknowledge being distracted at times by having a laptop computer available to them during class time.

Participant 1 said, "There were some distractions with games and videos, but overall I used it for mostly school stuff." Participant 3 said, "People just wouldn't pay attention in class or were doing something else. Participant 7 noted, "There were some distractions like games and stuff that distracted me, but I always got my homework done."Participant 6 stated:

I definitely got distracted when I had my laptop. I was definitely on other websites that I should not be on like Facebook and Twitter and emailing. And I feel like if I didn't have my laptop I couldn't do that because our teachers know when you have your phone out. I feel like I wouldn't be as distracted if I didn't have my laptop in front of me with Internet access. I would probably pay attention more.

Participant 11 echoed these statements by saying:

Definitely distractions went on. Like, you could always go on Facebook and people would try to figure out the password for playing games. One of my own issues was that I always wanted to play games instead of 
pay attention in class or study halls. You could also chat with people that were in your class, or outside of class, which was also a very big distraction for me.

Similarly, Participant 14 said:

I think about two kids every class would get disconnected with the class. It might be the kids that already know and they are just bored. And I think some other kids that just didn't care.

Students also gave credit to their teachers and schools for minimizing distractions when, over time, the teachers began to learn about websites and technology integration strategies. Participant 6 was one of these students, saying, "It's not about the technology but about how the teachers use the technology." He went on to say:

One disadvantage was sometimes you get off track and maybe play games, but later on our school adopted a firewall thing or something, and it blocked most of those websites. So, they (laptops) became more just for learning and students could not play games as much and mess around. You know like Facebook...they blocked that. They had a system where they could monitor what students are doing and could see the screen of the computer. They could stop it, and blink your screen, and when teachers even have a free period or time on their own in their classroom, they could look at student's computers in other classrooms. So, if they saw somebody on the game in say like a math class, and they knew they shouldn't be doing that; they (the teachers) could block them and tell the other teacher. Yeah it helped a lot.

Many of the study participants acknowledged the important role of the teacher in allowing or minimizing distractions related to the laptop. For instance, Participant 5 said, "Teachers that actually cared what students were doing on the laptops during class found a way to monitor students or asked students to keep their laptop lids closed." One comment from Participant 12 hinted at how teachers better effectively integrated the laptops for students as they learned about technology tools and resources:

Well, I think that basically the first-year we started using the laptops everyone was just getting the hang of it. Teachers and students were just getting the hang of the computers and how to use them. So, I feel we used them for notes and presentations more than anything to ease into it. A lot of times we used them for schoolwork, and then some of the teachers would start to use it for tests and other things like that. For my personal I used to check my email and I guess I watch movies. Almost all of my college classes utilize computers. For almost all of my classes I have to go online to find out grades and for assignments and discussions that I post online.

Participant 12 went on to say:

But when I was in senior, they were getting the hang of it. My brother is a sophomore and is doing a lot more online now. Some of my teachers I still talk to tell me they are now collaborating with other schools. I know Twitter is a big deal now too. It was a big deal when I was a senior so it just sounds like the program is getting better and better.

Other respondents also were quick to talk about the benefits for students in learning how to manage their laptop related to distractions. For example, Participant 3 said, "I feel like, I might have spent a lot more time with Facebook and stuff like games that may be on my computer because I didn't know, I wasn't ever exposed to that in the high school, but I also feel like I spent a lot more time just trying to figure out my computer."Participant 5 also gave credit to the laptop initiative for helping him to be more focused in college saying, "I think the advantages were that the laptop helped us get started for college, and how we would be using them in college. I think the disadvantage was there were websites and games that we used to play during class sometimes and that was a distraction." Many of these same participants also believed that being able to "play" and utilize a laptop during high school for personal and social entertainment has lead to a more productive first-year of college. For instance, Participant 10 said, "I feel like many college students who get a laptop for the first-year also are distracted by having a computer. I feel like since I had a laptop in high school I am able to better focus and be more productive now (in college)."

The participants clearly recalled experiences and situations in which the laptop or online sites or games that the laptop offered distracted them and/or their peers and were quick to note how teachers and school leaders handled the presented distractions. The effective ways that teachers can refocus students and limited laptop distractions by engaging students in integrated technology applications should be provided in pre-adoption skill development and on-going training. Knowing that having a laptop computer in the hands of every student, teacher preparation must instruct on how teachers can utilize the laptop computer for productive educational lessons rather than a routine inadvertent distraction tool. 


\section{Conclusion}

Data from the 1:1 study and Gartner's Hype Cycle offer guidance to school leaders for effectively incorporating new educational technologies. Gartner's Hype Cycle can play a key role in the timing of adopting technologies. For school leaders, the Hype Cycle can ensure money spent on technology is timely.

School leaders can also use the Hype Cycle to plan for and anticipate adoption issues related to new use of technologies for teaching and learning. Understanding the Hype Cycle provides leaders time to budget, write policy and procedures, and train staff for new technologies. Better anticipating technology adoption also allows school leaders to solicit buy-in from various stakeholder groups so that once technology is in hand it can fully be leveraged.

Results from the 1:1 suggest there are real benefits to having a laptop computer while in high school but without careful planning, student laptops may initially cause a productivity drop. The qualitative data in the 1:1 study offered guidance and direction for school leaders to minimize implementation issues, which can be summarized in three distinct themes:

- Technology initiatives in schools need to be well timed and have infrastructure to sustain them.

- Technology initiatives should have clear goals and measureable outcomes. Buy in from stakeholder groups about the desired goals and outcomes are vital to maximize the value of the initiative.

- Technology initiatives must include effective training for teachers prior to and during the adoption. Putting new technology in the hands of the staff before students has supreme benefits for teaching and learning.

School leaders spend considerable resources on technology initiatieves. Schools that are new to technology should move thoughtfully - and perhaps slowly - to ensure adequate short-term and long-term implementation. Gartner's Hype Cycle provides clear insight for school leaders as to when technology adoption is a safe and value-added investment. There is much that goes into a technology initiative and schools that "jump" in without enough planning or forethought may lose many of the gains that the innovation is designed to achieve.

\section{Acknowledgements}

There are two people in particular that deserve credit for helping to pull this article together. Tom Buckmiller, Associate Professor of Educational Leadership at Drake University provided overarching support to outline this article and help edit it along the way. Valerie Thacker served as the editor for this article. Thank you to both of them for their contribution toward making this article publishable and meaningful to readers.

\section{References}

Apple Computer, Inc. (2005). Research: What it says about 1:1 learning. Retrieved from http://ubiqcomputing.org/Apple_1-to-1_Research.pdf

Bogdan, R. C., \& Biklen, S. K. (1982). Qualitative research for education: An introduction to theory and methods. Boston: Allyn and Bacon, Inc.

CDW Government. (2011). 2011 CDW-G 21st-Century Classroom Report. Retrieved from http://webobjects.cdw.com/webobjects/media/pdf/newsroom/CDWG-21st-Century-Classroom-Report-0611 .pdf

Duncan, A. (2010, March 3). Using technology to transform schools. Remarks by Secretary Arne Duncan at the Association of American Publishers annual meeting. Retrieved from http://www2.ed.gov/news/speeches/2010/03/03032010.html

Fenn, J., \& Raskino, M. (2008). Mastering the Hype Cycle: How to choose the right innovation at the right time. Harvard Business Press.

Fenn, J., Raskino, M., \& Gammage, B. (2009). Gartner's hype cycle special report for 2009. Retrieved from http://www.gartner.com/DisplayDocument?id=1108412

Gartner, Inc. (2013). Gartner's hype cycle special report for 2013. Retrieved from http://my.gartner.com/portal/server.pt?showOriginalFeature=y\&open=512\&objID=260\&mode=2\&PageID $=3460702 \& \mathrm{id}=2574916 \& \mathrm{ref}=$

Gartner, Inc. (n.d). 25 September 2013. Retrieved from http://en.wikipedia.org/wiki/Gartner\#Press_coverage

Glaser, B. G., \& Strauss, A. M. (1967). The discovery of grounded theory: Strategies for qualitative research. New York, NY: Aldine. 
Guba, E. G., \& Lincoln, Y. S. (1994). Competing paradigms in qualitative research. In N. K. Denzin \& Y. S. Lincoln (Eds.), Handbook of qualitative research (pp. 105-117). Thousand Oaks, CA: Sage.

Marshall, E., \& Rossman, G. B. (1989). Designing qualitative research. Newbury Park, CA: Sage Publications, Inc.

Merriam, S. B. (1998). Qualitative research and case study applications in education. San Francisco: Jossey-Bass Publishers.

Metiri Group. (2006). 1:1 learning: A review and analysis by the Metiri Group. Retrieved from http://www.k12blueprint.com/k12/blueprint/story_11_learning_a_review.php

Primary Sources: America's Teachers on America's Schools. (2010). America's teachers on America's schools: A project of Scholastic and the Bill \& Melinda Gates Foundation. Retrieved from http://www.Scholastic.com/primarysources/pdfs/Scholastic_Gates_0310.pdf

Project Tomorrow. (2011). Learning in the 21 $1^{\text {st }}$ Century; 2011 Trends Update. Retrieved from http://www.azed.gov/educational-technology/files/2011/09/k12trends2011_web.pdf

Sauers, N., \& McLeod, S. (2010). What does the research say about one-to-one initiatives? Castle Brief, No. 1. UCEA Center for the Advanced Study of Technology Leadership in Education, University of Kentucky. Retrieved from http://www.natickps.org/CASTLEBrief01_LaptopPrograms.pdf

Schifter, C. (2008). A Brief History of Computers, Computing in Education, and Computing in Philadelphia Schools. http://dx.doi.org/10.4018/978-1-59904-765-2.ch001

Strauss, A. M., \& Corbin, J. (1998). Basics of Qualitative Research: Techniques and Procedures for Developing Grounded Theory. (3rd Edition.). Newbury Park, CA: Sage Publications, Inc.

Wagner, T. (2008). The Global Achievement Gap: Why Even Our Best Schools Don't Teach The New Survival Skills Our Children Need--And What We Can Do About It. New York: Basic Books.

\section{$(\mathrm{cc}) \mathrm{BY}$}

This work is licensed under a Creative Commons Attribution 3.0 License. 